Check for updates

Cite this: RSC Adv., 2019, 9, 19780

Received 16th April 2019

Accepted 7th June 2019

DOI: $10.1039 / c 9 r a 02874 a$

rsc.li/rsc-advances

\section{Deposition amount and dissipation kinetics of difenoconazole and propiconazole applied on banana with two commercial spray adjuvants $\dagger$}

\author{
Jin Xu, Xiaofang Long, + Shijia Ge, Mengli Li, Lingzhu Chen, Deyu Hu \\ and Yuping Zhang (iD)*
}

\begin{abstract}
A rapid and sensitive method for the simultaneous determination of difenoconazole and propiconazole residues in banana matrices was established using GC-MS/MS. The average recovery rates of difenoconazole and propiconazole from various matrices ranged from $76.7 \%$ to $94.9 \%$. The relative standard deviation was between $0.9 \%$ and $7.4 \%$. The effect of adding organosilicon and mineral oil adjuvants after being applied to the residues of difenoconazole and propiconazole in banana leaves was examined. The initial deposition amount 2 hours after the adjuvant treatment with organosilicon and mineral oil was 1.22-2.13 times higher than that after water treatment. After adding the two spray adjuvants, the residues of the two pesticides at 2 hours on three samples followed the order leaves $>$ soil $>$ fruit. The degradation half-lives of the two pesticides were in the range of 1.91-7.30 days for all the three treatments in two typical banana-growing areas in China. The degradation half-lives of the two pesticides in the water treatment group and the mineral oil treatment group were similar. However, organosilicon could apparently increase the half-life of difenoconazole on banana leaves. The final levels of difenoconazole and propiconazole residues on whole banana fruits were $\leq 0.1 \mathrm{mg} \mathrm{kg}^{-1}$ (MRL) 14 days after application. The results of this work may aid the safe use of difenoconazole and propiconazole in banana production, especially when used with organosilicon and mineral oil adjuvants.
\end{abstract}

\section{Introduction}

Banana is a commonly consumed fruit rich in proteins, sugars, thiamine, vitamins, calcium, potassium and magnesium. In China, nearly 333000 hectares of land is earmarked for banana production, and the annual banana production is 9 million tonnes. ${ }^{1}$ In China, bananas are grown mainly in tropical and subtropical regions such as the provinces of Hainan, Guangxi, Guangdong and Yunnan. The leaf spot disease caused by Mycosphaerella musicola Mulder is the most serious and destructive banana disease and damages almost $50 \%$ of banana cultures each year. ${ }^{1-4}$ Various fungicides are used to control this disease and prevent serious crop losses in commercial banana production.

Triazole fungicides offer the benefits of protection, treatment and absorption and can prevent the growth and reproduction of fungi by inhibiting the synthesis of fungal cell wall

State Key Laboratory Breeding Base of Green Pesticide and Agricultural Bioengineering, Key Laboratory of Green Pesticide and Agricultural Bioengineering, Ministry of Education, Guizhou University, Guiyang 550025, P. R. China. E-mail: zhangyupinggz@163.com; Fax: +86851 88292090; Tel: +8685188292090

$\dagger$ Electronic supplementary information (ESI) available. See DOI: 10.1039/c9ra02874a

\$ The co-first author for this paper. sterols. $^{5}$ Triazole fungicides are classified as ergosterol biosynthesis-inhibiting fungicides, ${ }^{5}$ which can be applied directly to crops. ${ }^{6,7}$ These fungicides have protective and therapeutic effects and have been widely used to control crops such as grapes and bananas. ${ }^{8,9}$ The residues of difenoconazole and propiconazole in agricultural products and environmental samples have been mainly determined by HPLC-UV, ${ }^{\mathbf{1 0}}$ GCECD,$^{11}$ GC-FID ${ }^{12}$ and LC-MS/MS., ${ }^{9,13}$ However, only a few studies have been conducted on the simultaneous determination of the residues of propiconazole and difenoconazole in banana matrices.

The residual behaviour of the two fungicides when used alone or as mixtures towards crops and soils has been investigated previously. As an illustration, the behaviour of difenoconazole residues in Chinese cabbage, ${ }^{\mathbf{1 1}}$ rice and rice soils, ${ }^{15}$ and apples ${ }^{16}$ was determined. The behaviour of propiconazole residues in tomatoes, ${ }^{12}$ green tea sprouts, ${ }^{17}$ and ginseng ${ }^{18}$ was studied. The behaviour of difenoconazole and propiconazole mixtures in wheat and soils ${ }^{9}$ was investigated. Huan et al. determined the dissipation of difenoconazole and azoxystrobin in bananas, ${ }^{1}$ and Liu et al. investigated the dissipation of propiconazole in bananas. ${ }^{19}$ Huan et al. and Liu et al. examined only the behaviour of propiconazole and difenoconazole residues on the edible parts of bananas (namely, the whole fruit and 
the whole pulp) ${ }^{\mathbf{1 , 1 9}}$ but did not study their behaviour on banana leaves, which are the main targets of these pesticides.

Spraying adjuvants such as organosilicon and mineral oil can effectively reduce the surface tension of a drug solution and improve the wetting and spreading performance of the drug solution on the target. Several studies have reported that the addition of adjuvants can improve the control effect of pesticides; however, the changes or improvements vary with the plant species and the adjuvant class. ${ }^{20-26}$ For example, Teng et al. reported that atrazine mixed with organosilicon additives exerted remarkable synergistic effects on broadleaf weeds even when the dosage of organosilicon surfactants was only $0.1 \%$ of the spray volume. ${ }^{22}$ Akbar et al. found that mineral oil is a more efficient spray adjuvant for Beauveria bassiana against Tribolium castaneum larvae than a Silwet L-77 solution, in terms of spray suspension concentrations and the number of conidia that impinge on the target. ${ }^{24}$ Adjuvants can generally enhance the deposition, spread, penetration and uptake of pesticides. The amount of pesticide residues and the degradation rate may be influenced by the addition of adjuvants. However, various characteristics of the leaf surfaces of plants affect the performance of agrochemical sprays. Gaskin et al. found that organosilicon and sticker-spreader adjuvants can reduce the residual amount of acephate on easy-to-wet cucumber foliage but can increase the residual amount of acephate on difficult-towet pea foliage. ${ }^{27}$ Holloway et al. studied the effects of agral (polyoxyethylene nonylphenols), toil (methyl esters of rapeseed fatty acids) and bond (styrene-butadiene copolymers) adjuvants on the residues of diclofop and propiconazole on wheat and field beans, and they found that these adjuvants can increase the propiconazole residues on these crops. However, Agral and Bond did not increase the amount of diclofop residue on the crops. ${ }^{28}$ Ryckaert et al. reported that propiconazole and tolylfluanid can be mixed with different adjuvants for application on triticale and lettuce, respectively, which can increase the pesticide residues on the crop leaves. However, the dissipation of pesticides after adding the adjuvants was similar to that of the control group. ${ }^{29}$ Wang et al. found that oil adjuvants can increase the deposition of pyrimethanil and boscalid in greenhouse strawberries, but the degradation half-lives of pyrimethanil (5.2 and $4.2 \mathrm{~d}$ ) and boscalid (5.4 and $5.5 \mathrm{~d}$ ) were similar in the adjuvant treatment group and the control group. ${ }^{30}$ On spraying insecticides, banana trees grow taller, and this requires a high-pressure gasoline-powered sprayer. To reduce the intensity of work, farmers or banana growers often use a mixture of two or more formulations when applying pesticides. At the same time, in order to improve the effective utilisation of pesticides, many farmers and plantation operators often add spray adjuvants during the spraying of pesticides. The sale of spray additives in the market has made the addition of spray additives increasingly common. However, there is no research report on the effect of spray adjuvants on the residual behaviour of active pesticide ingredients in banana gardens.

This study established a simple, rapid and efficient analytical method based on GC-MS/MS for the simultaneous determination of difenoconazole and propiconazole residues on banana leaves, fruits and soils. Then, the residues and dissipation kinetics of difenoconazole and propiconazole were studied in two representative banana-growing regions of China; the banana trees selected were treated with or without organosilicon and mineral oil. Pesticide residues falling into the soil were identified. The food safety of the bananas treated with propiconazole and difenoconazole was also evaluated. This result provides a quantitative basis for the residual behaviour of propiconazole and difenoconazole with spray adjuvants and provides guidance for the proper use of organosilicon and mineral oils on bananas.

\section{Materials and methods}

\subsection{Chemicals and reagents}

The standards for difenoconazole (99.5\% pure) and propiconazole (99\% pure) were provided by Dr. Ehrenstorfer $\mathrm{GmbH}$ (Augsburg, Germany). A stock standard solution of difenoconazole $\left(200 \mathrm{mg} \mathrm{L}^{-1}\right)$ and propiconazole $\left(200 \mathrm{mg} \mathrm{L}^{-1}\right)$ was prepared in acetone. A mixed working standard solution of each pesticide at the concentrations of $0.005,0.02,0.05,0.2,1,2$, and $20 \mathrm{mg} \mathrm{L}^{-1}$ was prepared by volumetric serial dilution from each stock standard solution. All solutions were stored at $4{ }^{\circ} \mathrm{C}$ in the dark. Matrix-matched standards for each matrix were obtained by evaporating $1 \mathrm{~mL}$ of the solvent standard of each concentration at $45{ }^{\circ} \mathrm{C}$ and then dissolving in $1 \mathrm{~mL}$ blank samples extracted from each matrix.

Propiconazole (250 $\mathrm{g} \mathrm{L}^{-1}$ emulsifiable concentrate) and difenoconazole (37\% water-dispersible granules) were purchased from Syngenta, Ltd. and Syngenta Nantong Crop Protection Co., Ltd., respectively. Mineral oil (99\% emulsifiable concentrate) was purchased from Han Oil Energy Co., Ltd. Organosilicon (70\% emulsifiable concentrate) was purchased from Shandong Bestway Pesticide Co., Ltd. Analytical grade acetonitrile, ethanol, acetone and $n$-hexane were supplied by Jinshan Chemical Reagent Co., Ltd. (Chengdu, China). Distilled water was purchased from Watsons Corporation (Dongguan, China). Analytical grade anhydrous $\mathrm{Na}_{2} \mathrm{SO}_{4}$ and $\mathrm{NaCl}$ were purchased from the Youpu Reagent Company (Tianjin, China). Octadecylsilane $\left(\mathrm{C}_{18}\right)$, primary-secondary amine (PSA) and graphitised carbon black (GCB) were supplied by Agela Technologies (Tianjin, China).

\subsection{Determination of surface tension}

The surface tension of the liquid was measured using a fully automatic surface tension meter (SFZL-A) according to the national standard GB/T22237-2008. SFZL-A was purchased from Shanghai Yingnuo Precision Instrument Co., Ltd. The same sample was measured five times in succession. The measured surface tension values differed by $\leq 0.2 \mathrm{mN} \mathrm{m}^{-1}$. The measurement temperature was $25{ }^{\circ} \mathrm{C} \pm 2{ }^{\circ} \mathrm{C}$. Ultrapure water and ethanol were used for instrument calibration.

\subsection{Instrument conditions for propiconazole and difenoconazole analysis of GC-MS/MS}

The analysis was performed on Trace 1310 GC on a TSQ 8000 Evo mass spectrometer equipped with a TRIPLUS RSH 
Autosampler (Thermo Fisher Scientific, Waltham, USA). GC separation was performed using a TG-5ms capillary column (30 $\mathrm{m} \times 0.25 \mathrm{~mm}$ i.d. $\times 0.25 \mu \mathrm{m}$, Agilent Technologies, Santa Clara, USA). He (99.999\%) was used as the carrier gas at a constant flow rate of $1.2 \mathrm{~mL} \mathrm{~min}^{-1}$. The temperatures of the MS transfer line and the ion source were set at $280{ }^{\circ} \mathrm{C}$ and $300{ }^{\circ} \mathrm{C}$, respectively. The oven temperature was set to $90^{\circ} \mathrm{C}$, held for 1 minute, raised to $260{ }^{\circ} \mathrm{C}$ at a rate of $25{ }^{\circ} \mathrm{C} \min ^{-1}$, held for 3 minutes, raised to $290{ }^{\circ} \mathrm{C}$ at a rate of $10{ }^{\circ} \mathrm{C} \mathrm{min}^{-1}$ and held for 6 minutes. Programmed temperature vaporisation (PTV) of the temperature of the syringe was initially set at $80^{\circ} \mathrm{C}$ for 1 minute and then raised to $290^{\circ} \mathrm{C}$ at a rate of $10^{\circ} \mathrm{C} \mathrm{min}^{-1}$. A volume of $1.0 \mu \mathrm{L}$ was injected using $2 \mathrm{~mm}$ i.d. $\times 2.75 \mathrm{~mm} \times 120 \mathrm{~mm}$ PTV metal lining (Thermo Fisher Scientific, Waltham, USA) in split mode (no split). The qualitative ion pair of difenoconazole was 265/ 202, the collision energy was $18 \mathrm{eV}$, the quantitative ion pair was $265 / 139$, and the collision energy was $14 \mathrm{eV}$. Propiconazole has a qualitative ion pair of 172.9/109, collision energy of $16 \mathrm{eV}$, a quantitative ion pair of $172.9 / 145$, and collision energy of $24 \mathrm{eV}$. Multiple reaction monitoring was carried out in the positive mode. The retention times of propiconazole and difenoconazole were 10.30 and 15.45 minutes, respectively.

\subsection{Spray equipment}

The Fujitsu direct-coupled power sprayer was supplied by China Fujitec Co., Ltd. (Model: FST-25HD-1, displacement: $196 \mathrm{~cm}^{3}$, compression ratio: $8.5: 1$, maximum power: $3.8 \mathrm{~kW} / 3600 \mathrm{rpm}$, rated power: $4.0 \mathrm{~kW} / 3600 \mathrm{rpm}$ ).

\subsection{Field trials}

Field dissipation trials were conducted at Guangxi $\left(107^{\circ} 21^{\prime}-108^{\circ} 6^{\prime}\right.$ E, $\left.22^{\circ} 51^{\prime}-23^{\circ} 21^{\prime} \mathrm{N}\right)$ and Hainan $\left(109^{\circ}-110^{\circ} 15^{\prime} \mathrm{E}, 19^{\circ} 23^{\prime}-20^{\circ} 0^{\prime} \mathrm{N}\right)$, China. The two provinces are located in different monsoon climate zones. The environmental characteristics of the two research sites represent the environmental characteristics of the Chinese banana growing areas. Field trials were conducted from May 2018 to July 2018. The experiment involved three processing plots and one control plot. There were three parallel lines for each treatment. Each parallel line consisted of three banana trees, and each tree was separated by a buffer zone. The first treatment group (water group) was sprayed with a mixed aqueous solution of difenoconazole and propiconazole. The second treatment group (mineral oil group) was sprayed with a mixture of difenoconazole and propiconazole diluted with $1 \mathrm{~g} \mathrm{~L}^{-1}$ of aqueous mineral oil solution. The third treatment group (organosilicon group) was sprayed with a mixture of difenoconazole and propiconazole diluted with $1 \mathrm{~g}$ $\mathrm{L}^{-1}$ of the aqueous organosilicon solution. A similar amount of liquid (15.0-16 L) was used in each treatment.

We randomly collected approximately $1.0 \mathrm{~kg}$ of representative whole banana and banana leaf samples from each of the parallel plots to assess dissipation at 2 hours and 1, 2, 3, 5, 7, 10 and 14 days after spraying. We also randomly collected approximately $1.0 \mathrm{~kg}$ of soil $(0-5 \mathrm{~cm}$ depth) samples from each of the parallel plots 2 hours after spraying. All samples in the control group (whole banana, banana leaves and soil) were not exposed to the fungicides during their growth. Moreover, we collected $2 \mathrm{~kg}$ blank area control samples before spraying and on day 14 of sampling. Fresh samples were minced, homogenized, placed in polythene bags, shipped to the laboratory and stored at $-20{ }^{\circ} \mathrm{C}$ until analysis.

\subsection{Extraction and purification}

Banana leaves (about $10 \mathrm{~g}$ ) were weighed into a $100 \mathrm{~mL}$ centrifuge tube and mixed with $20 \mathrm{~mL}$ of acetonitrile, $20 \mathrm{~mL}$ of acetone, $3 \mathrm{~g}$ of sodium chloride and $5 \mathrm{~g}$ of anhydrous sodium sulphate. The sample was allowed to stand for 5 minutes after vortex mixing for 20 minutes and ultrasonic treatment for 20 minutes. Subsequently, $1 \mathrm{~mL}$ of the supernatant was collected, transferred to a $50 \mathrm{~mL}$ pear-shaped flask and concentrated at $45{ }^{\circ} \mathrm{C}$ using a rotary evaporator. The residue was dissolved in $1 \mathrm{~mL}$ of acetone and then mixed with $100 \mathrm{mg}$ of $\mathrm{C}_{18}$. The mixture was vortexed for 30 seconds and then filtered through a $0.22 \mu \mathrm{m}$ syringe filter prior to GC-MS/MS analysis. Whole banana and soil samples were extracted and purified in the same manner as that used for banana leaf samples.

\subsection{Method validation}

The performance of the method was validated according to a routine validation procedure including the following parameters: linearity, limit of quantitation (LOQ), matrix effect, accuracy and precision. The calibration curves for bananas, banana leaves and soils were drawn by plotting the peak areas for six or seven concentrations $(0.005,0.02,0.05,0.2,1,2$ and $\left.20 \mathrm{mg} \mathrm{L}^{-1}\right)$. Linearity between the solvent and matrix was evaluated by calibration curves, and the matrix effects were calculated. For linearity verification, the deviation of the backcalculated concentration from the true concentration $\leq \pm 20 \%$ was set as the criteria by the SANTE guide. ${ }^{31}$ LOQ is defined as the lowest spike level. ${ }^{32}$ The precision and accuracy of the recovery method were evaluated by using enhanced difenoconazole and propiconazole samples, three of which were in the fruit $\left(0.02,0.2\right.$ and $\left.2 \mathrm{mg} \mathrm{kg}^{-1}\right)$ and four concentration levels $\left(0.02,0.2,2\right.$ and $\left.20 \mathrm{mg} \mathrm{kg}^{-1}\right)$ in banana leaves and soil. Five of the spiked samples at different levels were prepared on three different days. The precision of the method was evaluated based on repeatability (intra-day) and reproducibility (inter-day), both expressed as relative standard deviation (RSD). The accuracy of the method was measured based on the relative standard deviations obtained from the spiked samples. ${ }^{32}$

In the current study, a solvent (acetone) standard curve and a matrix standard curve prepared based on control sample extracts were used to determine the matrix effect (ME). The calculation of $\mathrm{ME}$ was based on the following equation:

$$
\begin{aligned}
\operatorname{ME}(\%) & =100 \times[\text { slope }(\text { matrix }) \\
& - \text { slope }(\text { solvent })] / \text { slope }(\text { solvent })
\end{aligned}
$$

Here, slope (matrix) and slope (solvent) are the slopes of the calibration curves of the matrix and solvent standards, respectively., ${ }^{\mathbf{9} 33,34}$ The matrix effect was divided into three levels: (1) $|\mathrm{ME}| \leq 20 \%$ was considered a weak matrix effect or no matrix effect; (2) $|\mathrm{ME}|$ between $20 \%$ and $50 \%$ was considered 

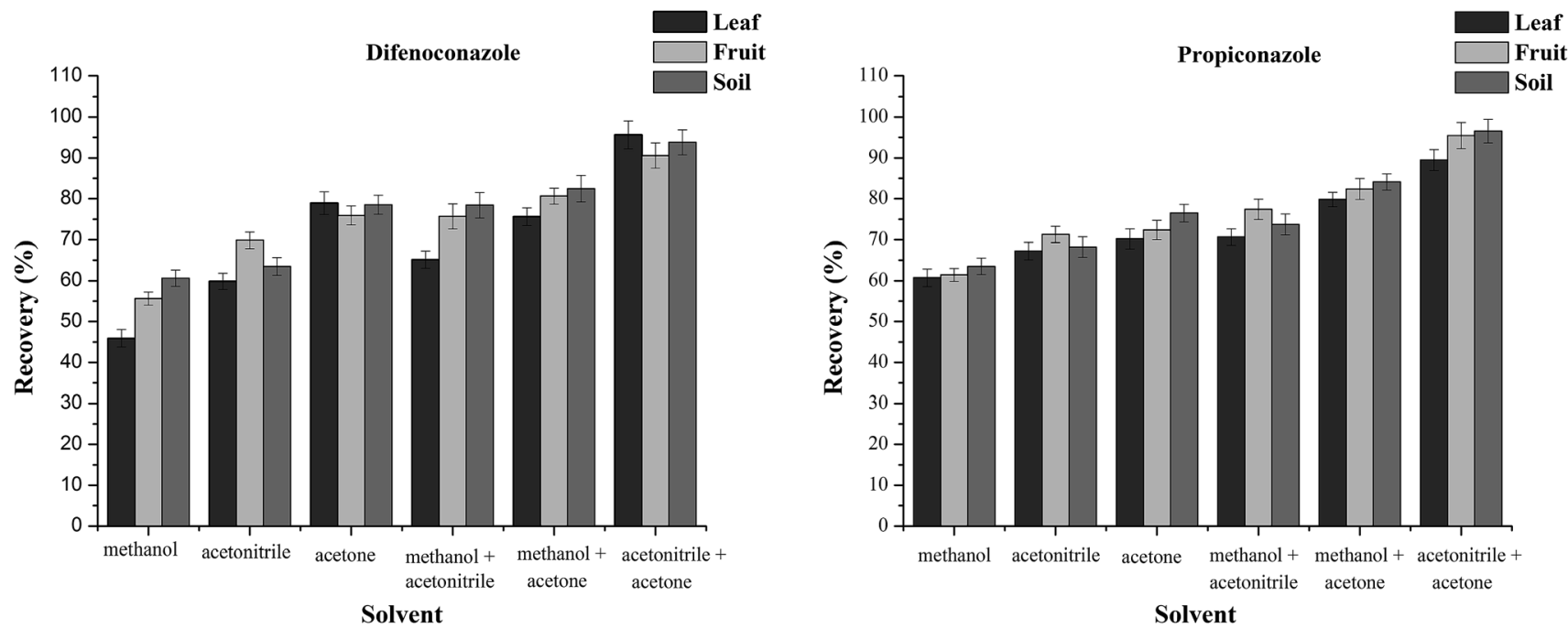

Fig. 1 Effect of different solvents on difenoconazole and propiconazole in the leaf, fruit and soil matrices.

moderate; (3) |ME greater than $50 \%$ was considered as a strong matrix effect. ${ }^{35}$

\section{Results and discussion}

\subsection{Optimization of the extraction procedure}

Acetonitrile and acetone are the most commonly used extractants in the extraction of difenoconazole and propiconazole from banana fruit and other matrices. ${ }^{1,9,36}$ In this study, three organic solvents and their combinations (methanol, acetonitrile, acetone, methanol + acetonitrile, methanol + acetone and acetone + acetonitrile) were selected as extraction solvents to study their efficiency in extracting the two analytes (Fig. 1). In the extraction of banana leaves, whole fruits and soils, when extracted with acetonitrile and acetone $(\mathrm{v}: \mathrm{v}=1: 1)$, the recoveries were $89.4 \%-95.6 \%, 90.6 \%-95.5 \%$ and $93.8 \%-96.5 \%$, respectively. The recovery rates of the other five extracts of banana leaves, whole fruits and soils were in the ranges 45.9$79.8 \%, 55.6-82.4 \%$ and $60.6-84.1 \%$, respectively. Thus, the mixture of acetonitrile and acetone $(\mathrm{v}: \mathrm{v}=1: 1)$ afforded the best extraction rate for difenoconazole and propiconazole.

Dispersive solid phase extraction (dSPE, PSA, $\mathrm{C}_{18}$, and GCB) is commonly used to separate pesticides from food and plant extracts for GC/MS/MS. ${ }^{37,38}$ In this work, dispersive solid phase extraction using cleaning agents PSA, $\mathrm{C}_{18}$, and GCB and their combinations was analysed for recovery and interference from the three matrices tested (Fig. 2). PSA is a weak anion exchange adsorbent that retains carboxylic acids, such as fatty acids, in the extract. $\mathrm{C}_{18}$ is a non-polar sorbent that effectively retains traces of lipids in the extract. In addition, GCB is commonly used to remove pigments. In the process of purifying banana leaves, fruits and soil matrix, the recovery rates with $\mathrm{C}_{18}(100$ $\mathrm{mg}$ ) as the cleaning agent were $89.4-92.4 \%, 98.3-105.4 \%$ and 95.8-102.2\%, respectively. In the other five purification methods, the recovery rates from banana leaves, fruits and soil matrix were $45.4-71.3 \%, 59.9-78.1 \%$ and $54.2-80.1 \%$, respectively. Therefore, $\mathrm{C}_{18}$ was used as the purifying agent in the purification process.
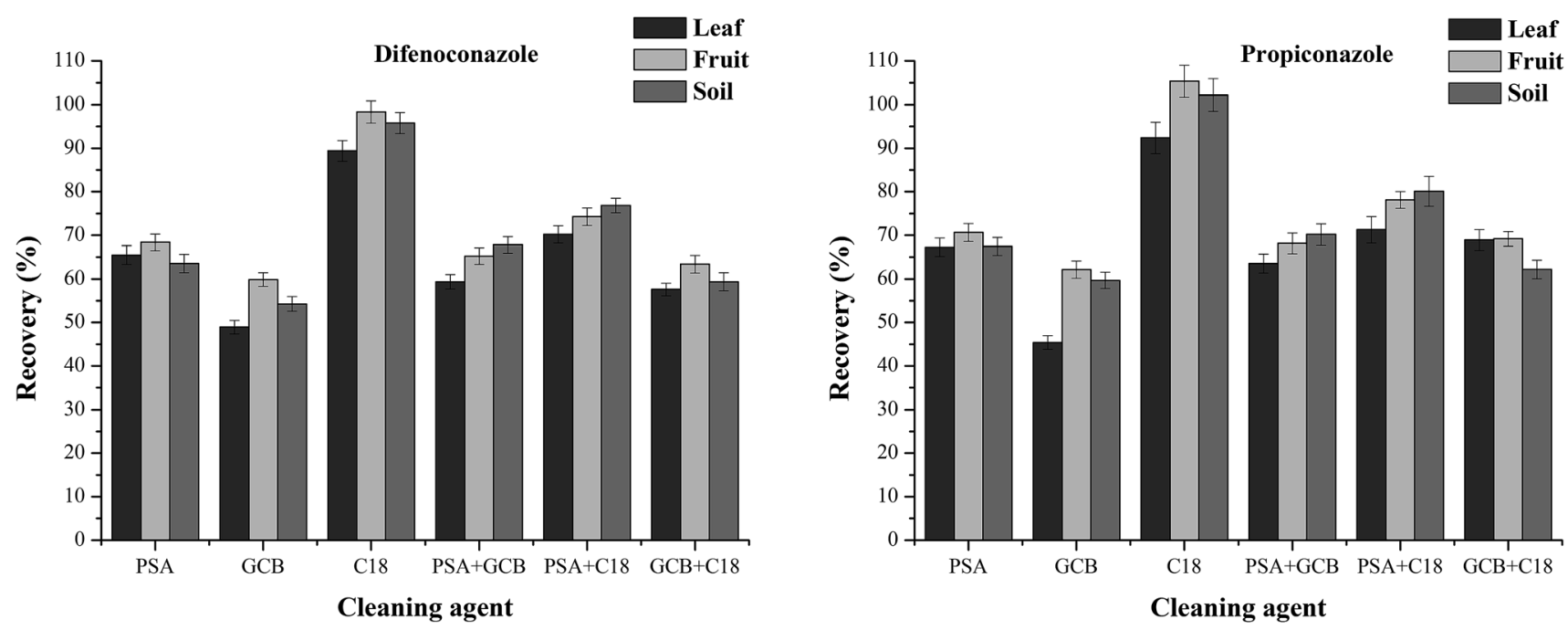

Fig. 2 Effect of different sorbents on difenoconazole and propiconazole in the leaf, fruit and soil matrices. 
Table 1 Calibration equation and correlation coefficient $\left(R^{2}\right)$ for each fungicide in each matrix

\begin{tabular}{lllllll}
\hline Compound & Matrix & Linear range $\left(\mathrm{mg} \mathrm{L}^{-1}\right)$ & Regression equation & $R^{2}$ & Deviation $^{a}(\%)$ & ME\% $^{2}$ \\
\hline \multirow{2}{*}{ Difenoconazole } & Acetone & $0.005-20$ & $y=4.23 \times 10^{8} x+1.17 \times 10^{5}$ & 0.9998 & \pm 18.8 & - \\
& Leaf & $0.05-20$ & $y=4.60 \times 10^{8} x+1.58 \times 10^{5}$ & 0.9999 & \pm 16.9 & 8.7 \\
& Whole fruit & $0.005-2$ & $y=4.33 \times 10^{8} x-1.16 \times 10^{5}$ & 0.9996 & \pm 18.5 & 2.4 \\
Propiconazole & Soil & $0.05-20$ & $y=4.35 \times 10^{8} x+3.11 \times 10^{5}$ & 0.9997 & \pm 17.3 & 2.8 \\
& Acetone & $0.005-20$ & $y=4.58 \times 10^{8} x+1.36 \times 10^{5}$ & 0.9997 & \pm 19.1 & - \\
& Leaf & $0.05-20$ & $y=5.00 \times 10^{8} x+7.1 \times 10^{5}$ & 0.9999 & \pm 16.6 & 9.2 \\
& Whole fruit & $0.005-2$ & $y=4.81 \times 10^{8} x-1.11 \times 10^{5}$ & 0.9997 & \pm 18.2 & 5.0 \\
& Soil & $0.05-20$ & $y=4.92 \times 10^{8} x+1.05 \times 10^{5}$ & 0.9998 & \pm 17.1 & 7.4
\end{tabular}

${ }^{a}$ The deviation of the back-calculated concentration from the true concentration (DG-SANTE, 2017).

\subsection{Method validation}

Matrix-matched calibration curves were plotted for six concentrations $\left(0.005,0.02,0.05,0.2,1,2\right.$, and $\left.20 \mathrm{mg} \mathrm{L}^{-1}\right)$ of difenoconazole and propiconazole in whole fruits, leaves, and soils. The calibration curve for each matrix (0.005-2 or 0.05$20 \mathrm{mg} \mathrm{L}{ }^{-1}$ ) was linear with a good coefficient of determination $\left(R^{2}>0.9996\right.$, Table 1$)$, and the deviations of back-calculated concentrations from true concentrations were $\leq \pm 20 \%$. $^{31}$ Matrix effects are common in GC-MS/MS. The matrix effect can be positive or negative, which mainly depends on the level of ion enhancement and inhibition. ${ }^{39}$ This can have a large impact on the accuracy and reproducibility of a method. ${ }^{35,40}$ The matrix effects of banana leaves, whole fruits and soils were obtained using formula (1). The matrix effects of the three matrices were

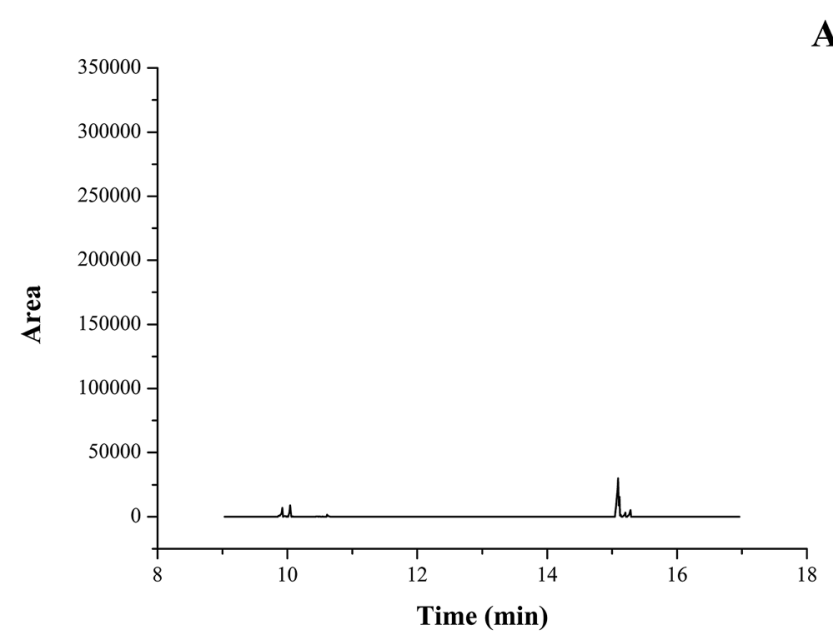

A
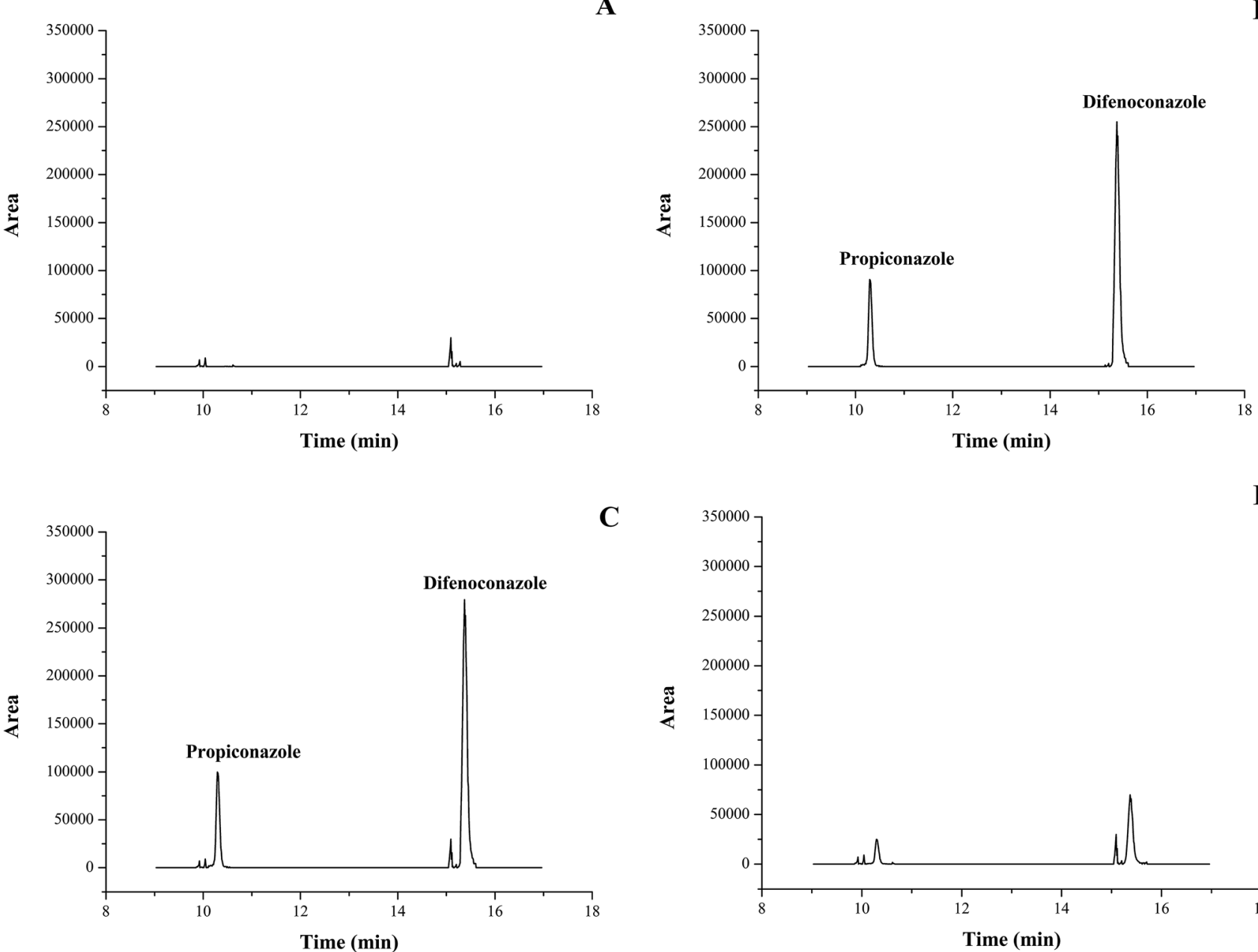

C

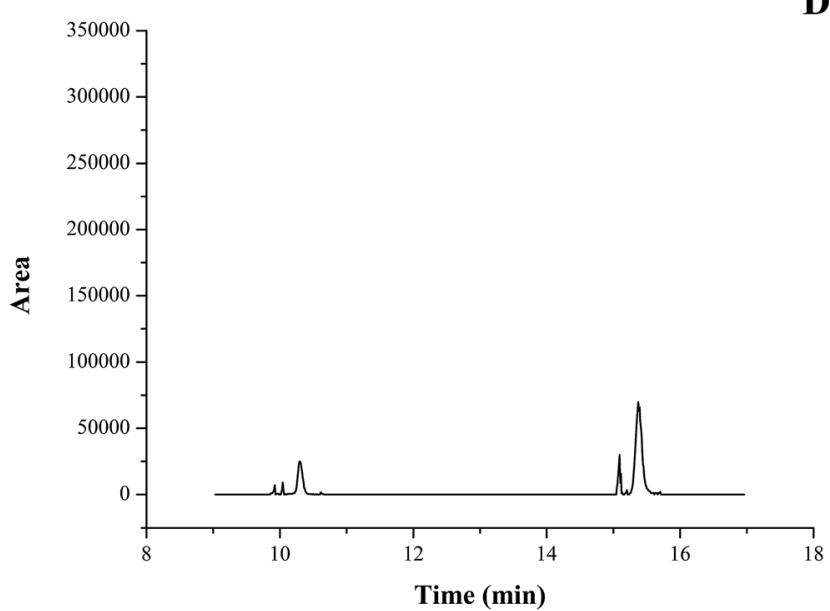

Fig. 3 Typical GC-MS/MS chromatograms of difenoconazole and propiconazole: (A) blank leaf sample, (B) standard solution (0.02 $\mu \mathrm{g} \mathrm{mL}^{-1}$ ), (C) matrix-matched standard solution $\left(0.02 \mu \mathrm{g} \mathrm{mL}^{-1}\right)$ and (D) leaf spiked sample $\left(0.02 \mathrm{mg} \mathrm{kg}^{-1}\right)$. 
Table 2 Difenoconazole and propiconazole recoveries in leaf, whole fruit and soil samples $(n=5)$

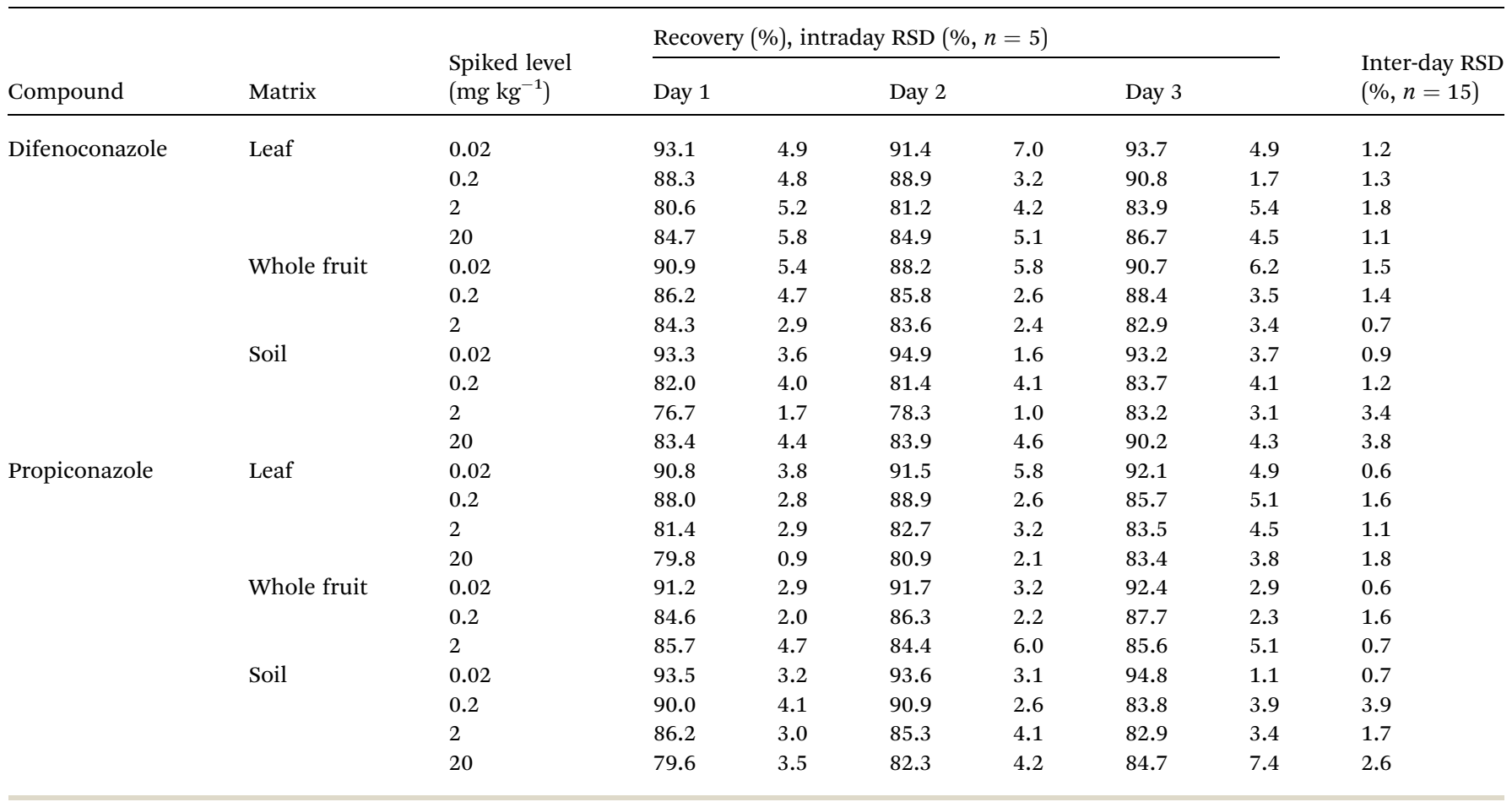

$<10 \%$ (Table 1). This showed that the weak matrix effects of banana leaves, whole fruits and soils could be attributed to the fact that only $1 \mathrm{~mL}$ extract of the total $40 \mathrm{~mL}$ extract was removed to be purified by $\mathrm{C}_{18}$ before GC-MS/MS analysis. In our study, matrix-matched standards were used to obtain more realistic data. The LOQ value of difenoconazole and propiconazole in the three matrices was $0.02 \mathrm{mg} \mathrm{kg}^{-1}$, which was lower than MRLs $\left(0.1 \mathrm{mg} \mathrm{kg}^{-1}\right)$ established by the Joint FAO/WHO Meeting on Pesticide Residues (JMPR). ${ }^{41}$ Fig. 3 shows the typical GC-MS/MS chromatograms of difenoconazole and propiconazole.

The accuracy and precision of the method were evaluated by recovery experiments. As shown in Table 2, the method exhibits satisfactory average recovery $(76.7-94.9 \%)$ and precision, and the
RSD values are $\leq 7.4 \%$ for all spiked concentration levels. The average recoveries of difenoconazole were from $76.7 \%$ to $94.9 \%$ with intra-day RSDs of $1.0-7.0 \%$ in banana leaves, whole fruits and soils. The average recoveries of propiconazole were from $79.6 \%$ to $94.8 \%$ with intra-day RSDs of $0.9-7.4 \%$ in the three matrices. The inter-day RSDs $(n=15)$ for this method ranged from $0.6 \%$ to $3.9 \%$. The results of the average recoveries and RSDs are in accordance with the guidelines in the SANTE guide. ${ }^{31}$

\subsection{Surface tension of aqueous organosilicon and mineral oil solutions}

We weighed about $0.1000 \mathrm{~g}$ (0.0001 precision) of organosilicon and mineral oil pesticide additives into a $100 \mathrm{~mL}$ volumetric flask, which was made up to volume with ultrapure water and
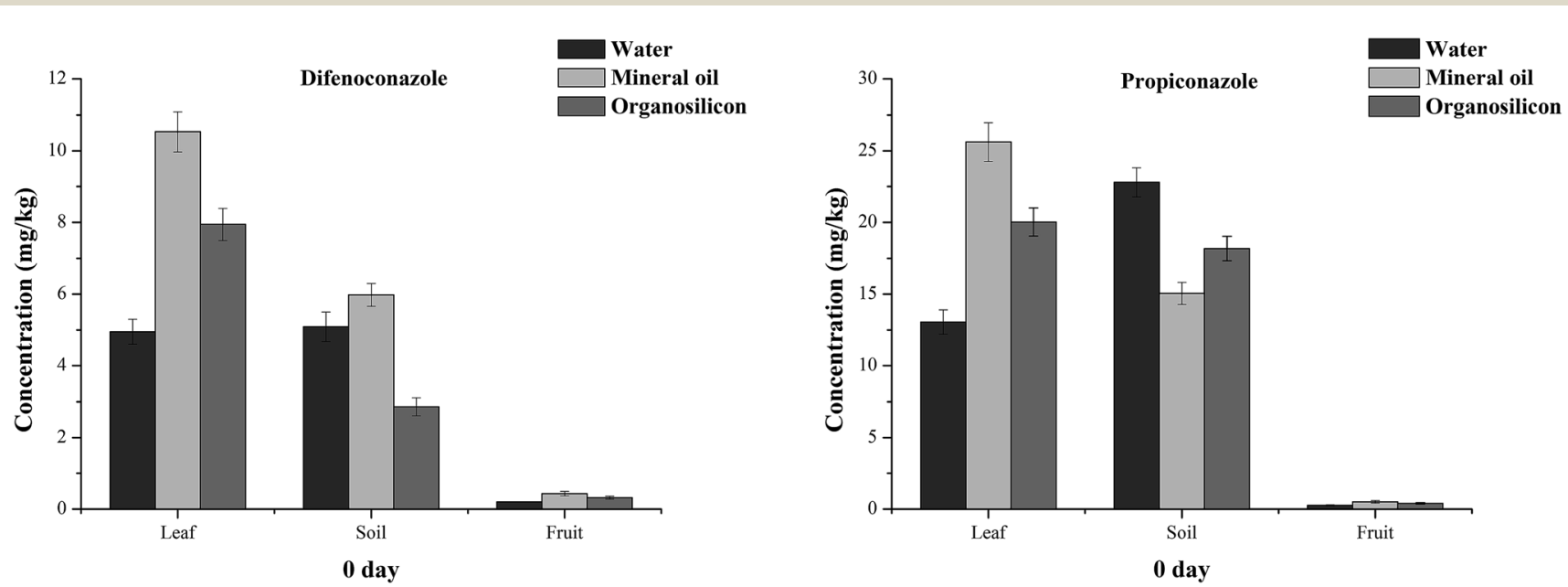

Fig. 4 The initial deposition amounts of difenoconazole and propiconazole in banana leaves, fruits and soils treated with water, organosilicon and mineral oil adjuvants at 0 day in Hainan. 

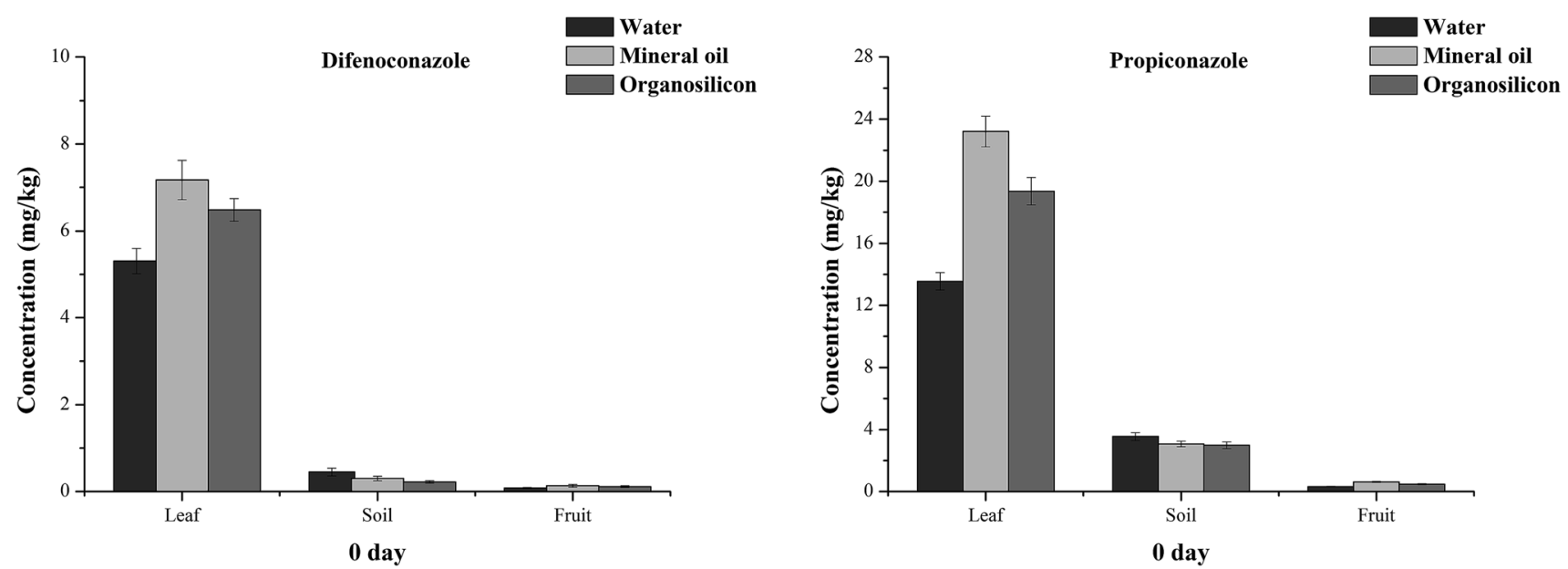

Fig. 5 The initial deposition amounts of difenoconazole and propiconazole residues on banana leaves, fruits and soils treated with water, organosilicon and mineral oil adjuvants at 0 day in Guangxi.

shaken thoroughly to prepare a $1000 \mathrm{mg} \mathrm{L}^{-1}$ solution; it was then diluted to concentrations of $800,700,600,500,250,100$ and $50 \mathrm{mg} \mathrm{L}^{-1}$. The surface tension of the $1000,800,700,600$, $500,250,100$ and $50 \mathrm{mg} \mathrm{L}^{-1}$ solutions was measured. The concentration surface tension curve of the solution was constructed (ESI, Fig. S1†). The surface tension decreased when the adjuvant concentration increased. The corresponding concentration at the inflexion point of the curve is the critical micelle concentration of the aqueous solution of an adjuvant. The results showed that the critical micelle concentrations of organosilicon additives and mineral oil additives were 780 and $650 \mathrm{mg} \mathrm{L}^{-1}$, respectively, and the surface tension values were 30.1 and $24.53 \mathrm{mN} \mathrm{m}^{-1}$, respectively. The smaller the surface tension of pesticide liquids, the smaller the contact angle between the liquid and the surface of the crop, which is helpful for wetting and spreading pesticide liquids on crop leaves. ${ }^{42-44}$ When the concentration of adjuvants is higher than the critical micelle concentration, the surface tension of the liquid does not change. Therefore, the concentration of organosilicon and mineral oil in the pesticide formulation was controlled at $1000 \mathrm{mg} \mathrm{L}^{-1}$. The two adjuvants reached their critical micelle concentration.
3.4 Effect of two adjuvants on the difenoconazole and propiconazole residue contents in banana leaves, fruits and soils at 2 hours after application

Organosilicon and mineral oil were added to the tested pesticides at the time of application. Fig. 4 and 5 show the residues of difenoconazole and propiconazole in banana leaves, fruits and soils after 2 hours. The initial deposition amounts of difenoconazole on banana leaves in the Hainan mineral oil, organosilicon and water groups were 10.53, 7.94 and $4.95 \mathrm{mg}$ $\mathrm{kg}^{-1}$, respectively, while those of propiconazole were 25.61, 20.02 and $13.05 \mathrm{mg} \mathrm{kg}^{-1}$, respectively (Fig. 4). The amounts of difenoconazole deposited 2 hours later in the banana leaves of the mineral oil and organosilicon groups were 2.13 and 1.60 times higher than those of the water group, respectively, and 1.96 and 1.53 times higher than those of propiconazole in banana leaves. The results in Guangxi were similar to those in Hainan. The initial amounts of difenoconazole and propiconazole deposition in the banana leaves of the mineral oil, organosilicon and water groups in Guangxi were 7.17, 6.48 and $5.31 \mathrm{mg} \mathrm{kg}^{-1}$ and $23.21,19.35$ and $13.55 \mathrm{mg} \mathrm{kg}^{-1}$, respectively (Fig. 5). The deposition amounts after $2 \mathrm{~h}$ in the banana leaves of the two spray additive groups were 1.22-1.71 times that of the

Table 3 Propiconazole and difenoconazole dissipation kinetics in banana leaves

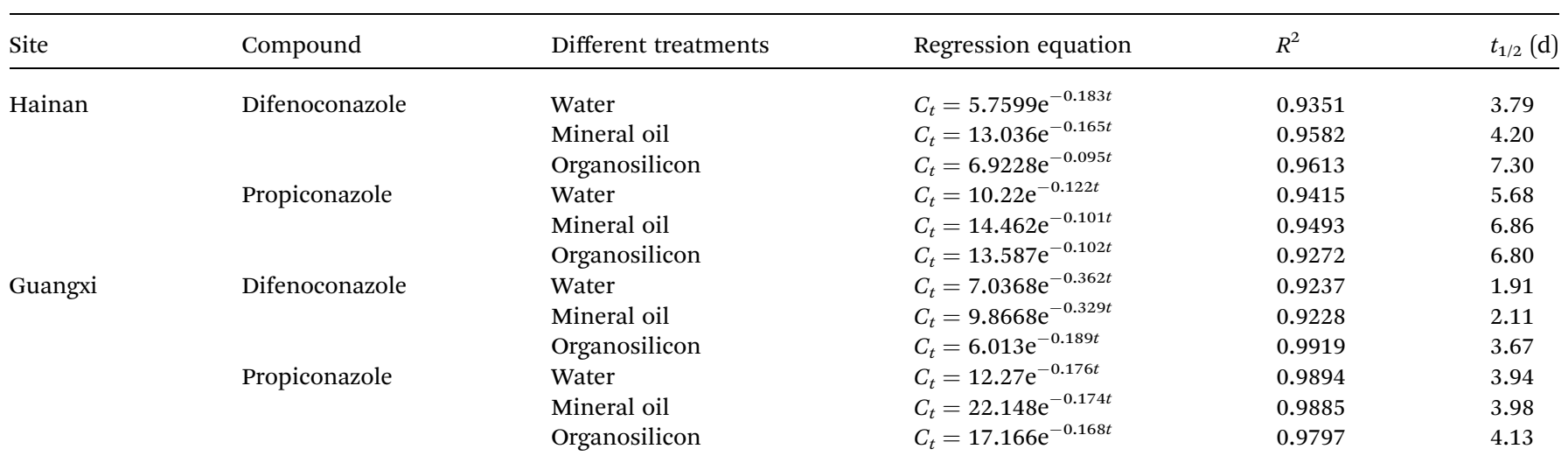


Guangxi water group. The results showed that the initial deposition amounts of difenoconazole and propiconazole in the banana leaves of the mineral oil and organosilicon treatment groups were higher than those of the water treatment groups at the two sites.

The residual content of difenoconazole and propiconazole in banana fruits 2 hours after application was studied. The initial deposition amounts of difenoconazole in the mineral oil, organosilicon and water treatment groups of Hainan were 0.43 , 0.32 and $0.20 \mathrm{mg} \mathrm{kg}{ }^{-1}$, respectively, and the propiconazole concentrations were $0.50,0.40$ and $0.26 \mathrm{mg} \mathrm{kg}^{-1}$, respectively (Fig. 4). The initial deposition amounts of difenoconazole in the fruits of the mineral oil, organosilicon and water groups of Guangxi were $0.13,0.11$ and $0.08 \mathrm{mg} \mathrm{kg}^{-1}$, respectively; the contents of propiconazole were $0.61,0.47$ and $0.31 \mathrm{mg} \mathrm{kg}^{-1}$, respectively (Fig. 5). These data indicate that the initial deposition in banana fruits is much lower than that on the leaves at the two locations. For example, in the water group of Hainan, the concentration of difenoconazole at 0 day was $4.95 \mathrm{mg} \mathrm{kg}^{-1}$ on the leaves and $0.20 \mathrm{mg} \mathrm{kg}{ }^{-1}$ on the banana fruits. The concentration of pesticides in leaves is about 25 times higher than that in fruits because pesticides are mainly used on leaves.

The residual contents of difenoconazole and propiconazole in the soil 2 hours after application were studied. In Hainan, the residues of difenoconazole in the mineral oil, organosilicon and water treatment groups were 5.98, 2.86 and $5.09 \mathrm{mg} \mathrm{kg} \mathrm{k}^{-1}$, respectively; the propiconazole contents were $15.05,18.18$ and $22.79 \mathrm{mg} \mathrm{kg}^{-1}$, respectively (Fig. 4). In Guangxi, for the mineral oil, organosilicon and water treatment groups, the residues of difenoconazole were $0.30,0.22$ and $0.45 \mathrm{mg} \mathrm{kg}^{-1}$, respectively, and the concentrations of propiconazole were 3.07, 2.99 and $3.55 \mathrm{mg} \mathrm{kg}{ }^{-1}$, respectively (Fig. 5). The amounts of the two pesticide residues in the Hainan soil samples far exceed those in Guangxi because the Hainan site is bare with no weed growth in the soil. It can be speculated that if there are no weeds in the Guangxi soil, the amount of pesticide residues falling into the soil will be much larger than that in the current soil. The results indicated that a significant amount of pesticides can remain in the soil of banana farms when the usual power jet sprayers are used.
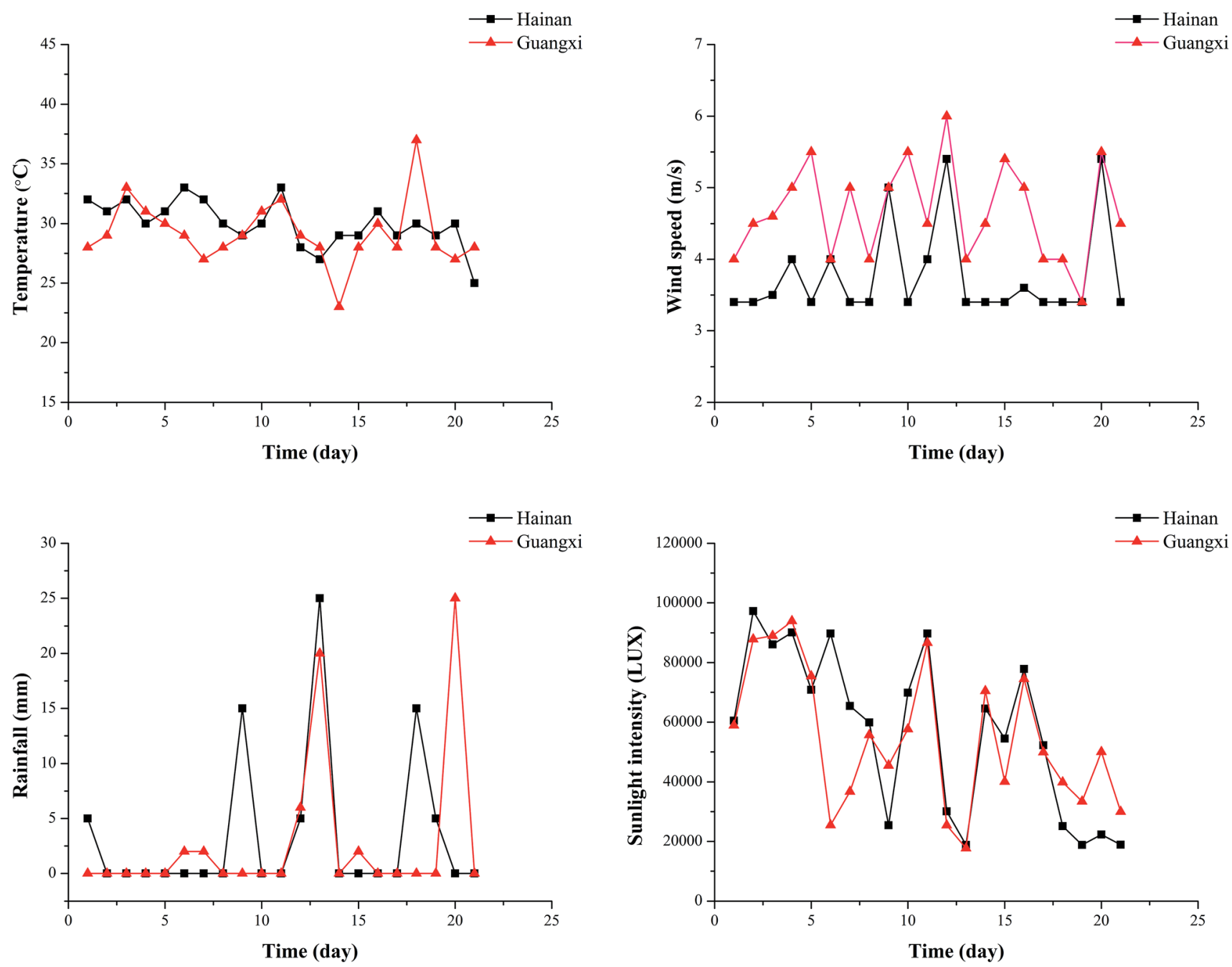

Fig. 6 Weather conditions (temperature, rainfall, sunlight intensity and wind speed) during field experiments in Hainan (May 16 to June 5 , 2018) and Guangxi (July 8 to July 28, 2018). 
It can be seen that the residues of the two pesticides in the Hainan (Fig. 4) leaves, soils and fruits after 2 hours are in the order soils $\geq$ leaves $>$ fruits in the water treatment group and the order is leaves $>$ soil $>$ fruit in the mineral oil and organosilicon treatment groups. The results show that the application of mineral oil and organosilicon additives can reduce the amount of pesticides entering the soil, thus decreasing the environmental pollution caused by pesticides.

\subsection{Dissipation kinetics of difenoconazole and propiconazole in banana leaves treated with two spray additives}

The trends of difenoconazole and propiconazole degradation on banana leaves followed first-order kinetics $\left(C_{t}=C_{0} \mathrm{e}^{-k t}\right)$, where $C_{t}$ is the concentration at time $t$ (days) after treatment, $C_{0}$ is the initial concentration at $2 \mathrm{~h}$ after application, and $k$ is the firstorder rate constant (1/day). The degradation half-life $\left(t_{1 / 2}\right)$ of difenoconazole or propiconazole under each experimental treatment was obtained on the basis of the equation $t_{1 / 2}=\ln (2) / k^{45-47}$

Degradation equations and degradation half-life results were calculated for different spray modes. The results are shown in Table 3. The degradation curve is shown in Fig. S2 in the ESI section. $\dagger$ The half-life of difenoconazole in the leaves treated with mineral oil, organosilicon and water in Hainan was 3.797.30 days, and those for Guangxi was 1.91-3.67 days. The halflife of propiconazole for the leaves of Hainan after the three treatments was 5.68-6.86 days and for Guangxi, the half-life was 3.94-4.13 days. It could be seen that the rate of degradation of the two pesticides on leaves in Guangxi was faster than that in Hainan. The degradation rate of pesticides is influenced by many factors including pesticide stability, frequency of application, initial concentration and weather (sunlight, temperature, humidity and wind). ${ }^{4-51}$ Different environmental conditions such as temperature, wind speed and sunlight intensity may explain the differences in the pesticide half-lives on the leaves between the two study sites. As shown in Fig. 6, the temperature and sunlight intensity in Hainan differ slightly from those in Guangxi, but the wind speed in Guangxi is higher than that in Hainan. Therefore, the rapid degradation of difenoconazole and propiconazole on leaves in Guangxi can be attributed to high wind speeds.

As shown in Table 3, the dissipation half-lives of propiconazole in leaves after treatment with water, mineral oil, and organosilicon in Hainan were 5.68, 6.86, and 6.80 days, and those in Guangxi were 3.94, 3.98, and 4.13 days, respectively. The dissipation half-lives of propiconazole after water treatment were almost the same as those of the two additive groups. The results showed that the two spray additives do not affect the degradation rate of propiconazole in the banana leaves. The dissipation half-lives of difenoconazole in leaves treated with water, mineral oil, organosilicon were $3.79,4.20$, and 7.30 days in Hainan and 1.91, 2.11, and 3.67 days in Guangxi, respectively. The half-lives of difenoconazole in the water groups were almost equivalent to those in the mineral oil group, both of which were apparently shorter as compared to that of the organosilicon groups. From this result, it is evident that mineral oils cannot

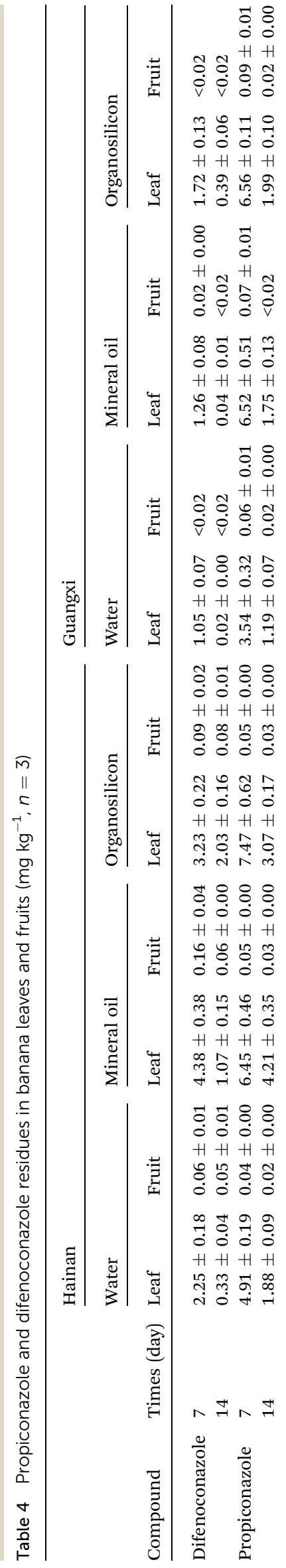


affect the degradation rate of the two triazole fungicides difenoconazole and propiconazole in banana leaves, but organosilicon can obviously increase the dissipation half-life of difenoconazole in banana leaves.

\subsection{Residues of difenoconazole and propiconazole in banana fruit}

The amounts of difenoconazole residues in pesticide-treated banana fruits across three treatment groups (water, mineral oil, organosilicon groups) at both sites were $<0.02-0.08 \mathrm{mg} \mathrm{kg}^{-1}$ (Table 4) 14 days after the application of the pesticide; the residues of propiconazole in the bananas treated with the pesticide in three treatments at both sites were $<0.02-0.03 \mathrm{mg}$ $\mathrm{kg}^{-1}$ (Table 4) 14 days after the application. These values are lower than the MRLs of $1 \mathrm{mg} \mathrm{kg}^{-1}$ and $1 \mathrm{mg} \mathrm{kg}^{-1}$ for difenoconazole and propiconazole, respectively, in bananas established by China; ${ }^{52}$ furthermore, they are also lower than the values of $0.1 \mathrm{mg} \mathrm{kg}^{-1}$ and $0.1 \mathrm{mg} \mathrm{kg}^{-1}$, respectively, established by the Joint FAO/WHO Meeting on Pesticide Residues. ${ }^{41}$ In addition, harvesting bananas 14 days after the last pesticide application can ensure food security by allowing sufficient time for the pesticides to degrade.

\section{Conclusions}

A rapid and sensitive method was established for the simultaneous determination of difenoconazole and propiconazole residues on banana leaves, fruits and soils. LOQ was $0.02 \mathrm{mg}$ $\mathrm{kg}^{-1}$ for both pesticides. The residues and dissipation kinetics of difenoconazole and propiconazole in bananas grown in two representative areas with two spray adjuvants were studied. The use of organosilicon adjuvants and mineral oil may increase the difenoconazole and propiconazole residues in banana leaves. When mineral oil was used as the adjuvant, it exhibited no effect on the rate of dissipation of the two pesticides on banana leaves. However, organosilicon could obviously increase the half-life of difenoconazole on banana leaves. Whole bananas possessed low levels of the residues of difenoconazole and propiconazole because both pesticides were mainly applied on the leaves. The samples taken at both sites possessed residue levels less than $0.1 \mathrm{mg} \mathrm{kg}^{-1}$, which is the MRL established by the Joint FAO/WHO Meeting on Pesticide Residues (JMPR), 14 days after the application of different adjuvants. The results of this study can facilitate the safe use of difenoconazole and propiconazole in banana production, particularly when these pesticides are used with organosilicon and mineral oil as adjuvants.

\section{Conflicts of interest}

The authors have declared that there are no conflicts of interest.

\section{Acknowledgements}

This work was supported by the Major State Research Development Program of China (No. 2016YFD0200206-3), the
National Natural Science Foundation of China (No. 21667007), and the Technology Programs of Guizhou Province (No. [2017] 5788) for the financial support.

\section{References}

1 Z. Huan, Z. Xu, D. Lv, D. Xie and J. Luo, Bull. Environ. Contam. Toxicol., 2013, 91, 734-738.

2 L. W. Sang and F. C. Zheng, J. Anhui Agric. Sci., 2006, 34, 1841-1845.

3 R. Thangavelu, P. Sundararaju and S. Sathiamoorthy, J. Hortic. Sci. Biotechnol., 2004, 79, 664-668.

4 R. C. Ploetz and A. C. L. Churchill, Acta Hortic., 2011, 897, 519-526.

5 J. Rueegg and W. Siegfried, Crop Prot., 1996, 15, 27-31.

6 I. S. Kim, J. H. Shim and Y. T. Suh, Pest Manage. Sci., 2003, 59, 324-330.

7 Z. H. Li, V. Zlabek, J. Velisek, R. Grabic, J. Machova, J. Kolarova, P. Li and T. Randak, Environ. Toxicol., 2013, 28, 119-126.

8 G. P. Munkvold, P. M. Dixon, J. M. Shriver and C. A. Martinson, Phytopathology, 2001, 91, 477-484.

9 Z. Zhang, W. Jiang, Q. Jian, W. Song and Z. Zheng, Food Chem., 2015, 168, 396-403.

10 A. P. Pinto, C. Serrano, T. Pires, E. Mestrinho, L. Dias, D. M. Teixeira, et al., Sci. Total Environ., 2012, 435, 402-410.

11 H. Wang, T. Yong, D. M. Qin, Y. Gong and Y. Ji, Chin. Chem. Lett., 2008, 19, 969-972.

12 T. K. Panovska, Z. Kavrakovski and S. Bauer, Bull. Chem. Technol. Maced., 2000, 19, 27-33.

13 Z. Q. Kong, F. S. Dong, J. Xu, X. G. Liu, C. P. Zhang, J. Li, et al., Food Control, 2012, 23, 542-546.

14 S. Wu, H. Zhang, K. Zheng, B. Meng, F. Wang, Y. Cui, et al., Biomed. Chromatogr., 2017, 32, e4052.

15 K. Wang, J. X. Wu and H. Y. Zhang, Ecotoxicol. Environ. Saf., 2012, 86, 111-115.

16 C. Guo, J. Z. Li, B. Y. Guo and H. L. Wang, Bull. Environ. Contam. Toxicol., 2010, 82, 427-431.

17 K. Chinnachamy and M. Narayanannair, J. Sci. Food Agric., 2010, 89, 1851-1856.

18 C. Wang, Y. Wang, R. Wang, J. Yan, Y. Lv, A. J. Li and J. Gao, Int. J. Environ. Anal. Chem., 2017, 97, 1-13.

19 Y. J. Liu, Y. Fan, X. G. Zhang, X. R. Li and Y. Q. Zheng, Plant Prot., 2010, 36, 109.

20 L. L. Shi, Study on the improvement of pesticide deposition by adjuvant, Chinese Academy of Agricultural Sciences, 2006.

21 P. Zhang, Study on residue and degradation of tristylphenol ethoxylates pesticide adjuvant in agro-product, Chinese Academy of Agricultural Sciences, 2007.

22 C. H. Teng, L. B. Zhang, Q. Y. Wang and B. Tao, J. Northeast Agric. Univ., 2011, 42, 71-75.

23 G. Rousseau, P. Coutanceau, F. Lebeau, O. Pigeon, N. Ducat and V. P. De, Commun. Agric. Appl. Biol. Sci., 2013, 78, 121132.

24 W. Akbar, J. C. Lord, J. R. Nechols and T. M. Loughin, J. Econ. Entomol., 2005, 98, 683-688. 
25 F. C. Roggenbuck, D. Penner, R. F. Burow and B. Thomas, Pestic. Sci., 1993, 37, 121-125.

26 M. Singh and R. E. Mack, Pestic. Sci., 1993, 38, 219-225.

27 R. E. Gaskin, R. J. Murray, H. Krishna and A. Carpenter, N. Z. Plant Prot., 2000, 53, 355-359.

28 P. J. Holloway and N. M. Western, Pest Manage. Sci., 2003, 59, 1237-1244.

29 B. Ryckaert, P. Spanoghe, G. Haesaert, B. Heremans, S. Isebaert and W. Steurbaut, Crop Prot., 2007, 26, 15891594.

30 Z. W. Wang, X. Q. Wang, T. Cang, X. P. Zhao, S. G. Wang, P. P. Qi, X. Y. Wang, X. H. Xu and Q. Wang, Ecotoxicol. Environ. Saf., 2018, 160, 127-133.

31 DG-SANTE, Guidance Document on Analytical Quality Control and Method Validation Procedures for Pesticides Residues Analysis in Food and Feed. Document SANTE/11813/2017, European Commission, 2017.

32 X. M. Shi, F. Jin, Y. T. Huang, X. W. Du, C. M. Li, M. Wang, H. Shao, M. J. Jin and J. Wang, J. Agric. Food Chem., 2012, 60, 60-65.

33 J. Jang, M. M. Rahman, A. Y. Ko, A. M. A. El-Aty, J. H. Park, S. K. Cho and J. H. Shim, Food Chem., 2014, 146, 448-454.

34 J. Gong, K. Zheng, G. Yang, S. Zhao, D. Y. Hu and K. K. Zhang, Food Addit. Contam., Part A, 2019, 9, 1-11.

35 N. Besil, V. Cesio, H. Heinzen and A. R. Fernandez-Alba, J. Agric. Food Chem., 2017, 65, 4819-4829.

36 R. L. Hu, D. X. Gao, L. N. Liu, Y. L. Wang and J. Chen, Agrochemicals, 2010, 49, 194-196.

37 Á. Grande-Martínez, J. L. Martínez-Vidal, M. E. HernándezTorres and A. Garrido-Frenich, Food Anal. Methods, 2016, 9, 548-563.
38 S. Walorczyk and D. Drożdżyński, J. Chromatogr. A, 2012, 1251, 219-231.

39 D. Kang, H. Zhang, Y. Chen, F. Wang, L. H. Shi, D. Y. Hu and K. K. Zhang, Biomed. Chromatogr., 2017, 31, e3987.

40 J. Xu, F. S. Dong, X. G. Liu, J. Li, Y. B. Li, W. L. Shan and Y. Q. Zheng, Bull. Korean Chem. Soc., 2011, 32, 4265-4269.

41 JMPR (The Joint FAO/WHO Meeting on Pesticide Residues), JMPR Report: Propiconazole and Difenoconazole, 2007, http:// www.fao.org/agriculture/crops/thematic-sitemap/theme/ pests/lpe/lpe-p/en/.

42 J. Janku, L. Bartovska and J. Soukup, Plant, Soil Environ., 2012, 58, 568-572.

43 Z. L. Zhou, C. Cao, L. D. Cao, L. Zheng and Q. L. Huang, PLoS One, 2017, 12, e0176870.

44 L. Xu, H. Zhu, H. E. Ozkan, W. E. Bagley, R. C. Derksen and C. R. Krause, Trans. ASABE, 2010, 53, 13-20.

45 Q. Ma, A. Rahman, P. T. Holland, T. K. James and D. E. McNaughton, J. Environ. Qual., 2004, 33, 930-938.

46 Z. Y. Zhang, W. L. Shan, W. C. Song, Y. Gong and X. J. Liu, Environ. Chem. Lett., 2011, 9, 547-552.

47 B. Yan, F. Ye and D. Gao, Pest Manage. Sci., 2015, 71, 65-71. 48 P. Fantke and R. Juraske, Environ. Sci. Technol., 2013, 47, 3548-3562.

49 M. X. Lu, W. W. Jiang, Q. Jian, Y. Shen, X. J. Liu and X. Y. Yu, PLoS One, 2014, 11, e100556.

50 Z. Y. Zhang, W. Jiang, Q. Jian, W. C. Song, Z. T. Zheng and C. J. Ke, J. Agric. Food Chem., 2014, 62, 1221-1226.

51 N. Besil, A. Pérez-Parada, F. Bologna, M. V. Cesio, F. Rivas and H. Heinzen, Sci. Hortic., 2019, 248, 34-40.

52 Ministry of Agriculture, National food safety standard maximum residue limits for pesticides in food. (GB 2763), People's Republic of China, 2016. 